\title{
Photosynthesis.
}

GREAT interest was taken in the joint discussion on photosynthesis between the sections of Chemistry and Botany during the British Association meeting at Hull. The discussion was presided over by Prof. H. H. Dixon, who was supported by Principal J. C. Irvine.

The discussion was opened by Dr. F. F. Blackman with a paper entitled "The biochemical problems of chloroplastic photosynthesis." Dr. Blackman said that as the next two speakers were to take up the special aspects of photochemistry and energetics he would restrict his remarks to certain other aspects. He would deal with the active system of photosynthesis and its organisation in the living cell and bring together the evidence which supported the thesis that here we have to do, not with a simple photochemical reaction, but with a complex system in which other components, that might be described provisionally as protoplasmic components, play an essential part.

The first point developed was that there are numerous lower plants which obtain all their carbon by the reduction of $\mathrm{CO}_{2}$ in the dark without the intervention of radiation, and synthesise all their organic compounds from this source. Here there is utilised the chemical energy of the oxidation of nitrogen, sulphur, or their compounds. In these chemosynthetic organisms there is not a gain of energy, but only an exchange of oxidation potential: the gain to the organism is substance for growth. It may be asked whether this power is entirely absent in the higher plants and what connexion the chemical machinery of it has with the chemistry of photoreduction of $\mathrm{CO}_{2}$

The second point was the fact, now thoroughly investigated, that the seedlings of many plants at a stage when they have developed chlorophyll to a full green colour may be quite incapable of reducing $\mathrm{CO}_{2}$ in light, and give out as much $\mathrm{CO}_{2}$ from respiram tion in light as in darkness. Some other component or property lags behind the chlorophyll in its development, and the slow, steady rate of its development is the same in darkness or light.

A third point of interest is the efficiency of photosynthesis in the golden-leaved varieties of certain shrubs. Here the amount of chlorophyll may be as low as 4 per cent. of the normal green form and yet under medium conditions the reduction of $\mathrm{CO}_{2}$ may be as great as in green leaves. The fact has been established that the golden leaf needs more light than the green to carry out the same rate of reduction of $\mathrm{CO}_{2}$. It looks as if with these extreme variations of chlorophyll what counted was the cube root of the amount of chlorophyll present-a single dimension of the colloid micellæe and not the total mass-which may be taken as an indication of the organisation of the system.

A fourth point considered was the relation of photosynthesis to temperature. It is established that for a high rate of photosynthesis it is not sufficient to have intense radiation and concentrated $\mathrm{CO}_{2}$, but a high temperature is also essential. For each temperature there is a specific maximum of activity which cannot be exceeded unless the temperature is raised. The specific maximal values increase rapidly for rising temperature, having a temperature coefficient of about 2 for a rise of $10^{\circ} \mathrm{C}$. This temperature relation is quite different from that of a pure photochemical reaction, and it provides a further indication that we have to deal with a complex system in which dark reactions may play a controlling part.
The fifth point to be raised had to do with the organisation of the active system. Warburg in investigating the action of the narcotic phenylurethane upon the rate of photosynthesis finds that the process undergoes great depression of rate with perfect recovery on removal of the narcotic. The relation of the depression to the external concentration. of the drug gives a typical adsorption isotherm, indicating that the narcotic acts by adsorption on a surface from which it displaces temporarily some reactant substance of the active photosynthetic system.

Taking all these pieces of evidence together, Dr. Blackman considered that we are forced to conclude that the chloroplast contains an active system of several components related together in a complex organisation.

Prof. E. C. C. Baly then presented the results of experimental work on photosynthesis carried out at Liverpool. The conversion of a substance A into substance B might, he said, be represented as the sum of the three equations :

$$
\begin{aligned}
\mathrm{A}+\mathrm{E} & =\mathrm{A}^{\prime} \\
\mathrm{A}^{\prime} & =\mathrm{B}^{\prime}+\mathrm{F} \\
\mathrm{B}^{\prime} & =\mathrm{B}+\mathrm{G}
\end{aligned}
$$

where $E, F$, and $G$ are quantities of energy and $A^{\prime}$ and $B^{\prime}$ represent the reactive forms of $A$ and $B$. The reaction is exo- or endo-thermic according as $\mathrm{F}+\mathrm{G}-\mathrm{E}$ is positive or negative. In any case a quantity of energy, $\mathrm{E}$, must be supplied in order to start the reaction, and this may be done by means of (I) heat, (2) light, or (3) a material catalyst. Now the energy can only be supplied in " quanta," and if $\mathrm{E}$ is large, only the use of radiation of short wave-length makes the number of "quanta" to be introduced sufficiently small to be practicable. For the conversion of a molecule of carbonic acid into formaldehyde and oxygen 150,000 calories are necessary, and this can be supplied in a single quantum by radiation at wave-length $200 \mu \mu$. Carbonic acid has an absorption band at this frequency and formaldehyde ought therefore to be produced when a solution of $\mathrm{CO}_{2}$ in water is exposed to ultra-violet light. This has now been shown to take place.

In order to bring about the reaction by means of visible light it is necessary to have present a coloured substance with basic properties, and Malachite Green has been found to fulfil the conditions. There seems little doubt that the formation of formaldehyde in the leaf takes the following course :

i. Chlorophyll $\mathrm{A}+\mathrm{H}_{2} \mathrm{CO}_{3}+$ light $=$ Chlorophyll $\mathrm{B}+\mathrm{CH}_{2} \mathrm{O}$.

ii. Chlorophyll $\mathrm{B}+$ Carotin $=$ Chlorophyll $\mathrm{A}+\mathrm{Xanthophyll}$

iii. Xanthophyll +light $=$ Carotin + Oxygen .

The photosynthesised formaldehyde is extraordinarily reactive and is best represented by the formula $\mathrm{CHOH}$. It is polymerised rapidly to a mixture of carbohydrates, in which are found hexoses (20 per cent.), cellulose, and cane-sugar. In the presence of nitrite it is converted into formhydroxamic acid and hence into amino-acids and a mixture of cyclic bases in which pyrrole, pyrrolidine, pyridine, coniine and glyoxaline have been detected. The active (energised) forms of the aminoacids are the immediate source of proteins.

Mr. G. E. Briggs described some experiments to determine the relation between the radiant energy absorbed and the carbon dioxide assimilated by the green leaf (Phaseolus vulgaris) in different parts of the visible spectrum. For three different parts of the spectrum the carbon dioxide assimilated was measured, and the energy absorbed by chlorophyll a 
and chlorophyll $b$ was estimated from data obtained, due allowance being made for the energy diffusely reflected by the leaf. The results were of the following order: for the yellow-red $(570-640 \mu \mu)$, I 5 calories per c.c. of carbon dioxide, for the green (5 $10-560 \mu \mu), 7$, and for the blue $(430-5$ го $\mu \mu), 22+$, these being maximal values.

Mr. Briggs pointed out that since the heat of formation of the most probable products of assimilation ranges from five to six and more calories per c.c. of carbon dioxide, the indications are that both chlorophyll $a$ and chlorophyll $b$ take part in the photochemical reaction. Referring to Prof. Baly's suggestions as to the part played by the different pigments in the photosynthetic process, he said that since the quantity of each pigment underwent relatively little change during prolonged assimilation no energy was supplied from this source, and, further, that since as much oxygen was evolved as carbon dioxide absorbed in the red and the green parts of the spectrum--regions where no energy is absorbed by the xanthophyll-as well as in the blue, it was not necessary to postulate a photochemical reaction involving xanthophyll in order that oxygen might be liberated.

Prof. I. M. Heilbron and Mr. C. Hollins put forward some speculations on photosynthesis. The large number of plant products in which the predominant carbon nucleus is $\mathrm{C}_{5}$ or a multiple of this suggests that this unit has a special significance. The photosynthesised reactive hexose may be supposed, in addition to its further condensation to sugars, cellulose, glucosides, etc., to furnish by dehydration $\omega$-hydroxymethylfurfural. This by oxidation and decarboxylation can give a stabilised $\mathrm{C}_{5}$ compound, which, either as the furan derivative or (by opening of the ring) as dihydroxyglutaconic dialdehyde, may be a source of pentoses and of condensation products of these. Simple schemes were suggested showing how two, or three, molecules of a "pentose" can give rise by ordinary condensation reactions to anthocyans $\left(\mathrm{C}_{15}\right)$, terpenes $\left(\mathrm{C}_{5}, \mathrm{C}_{10}, \mathrm{C}_{15}\right.$, etc. $)$, coniferyl alcohol $\left(\mathrm{C}_{9}\right)$, and the numerous related compounds, coniine $\left(\mathrm{C}_{8}\right)$ and the phonopyrrolecarboxylic acids $\left(\mathrm{C}_{8}\right.$, etc. $)$. The degradation of hexose into " pentose" represents the respiration of the plant. Against the suggestion of Robinson (British Assoc., I92I) that anthocyans result from the condensation of two hexose and one triose molecule are to be set the absence of nonoses in Nature and the failure of all attempts to obtain benzene derivatives from hexoses.

Papers were also contributed by Dr. F. C. Eve and Prof. M. C. Potter.

Prof. R. Robinson thought that the accumulation of active formaldehyde and formhydroxamic acid scarcely accounted for the almost inexhaustible variety of plant products. The alkaloids were probably produced from hexoses rather than built up atom by atom from formaldehyde. $\mathrm{He}$ was unable to accept the suggestions of Prof. Heilbron and $\mathrm{Mr}$. Hollins as to the significance of the $\mathrm{C}_{5}$ unit. The anthocyans he preferred to consider as $\mathrm{C}_{6}+\mathrm{C}_{3}+\mathrm{C}_{6}$ rather than $\mathrm{C}_{5}+\mathrm{C}_{5}+\mathrm{C}_{5}$. Although nonoses had not been found in Nature, E. Fischer had obtained a nonose which was fermentable.

Dr. E. F. Armstrong emphasised the importance of cane-sugar in the carbohydrate metabolism of green leaves.

Prof. Baly briefly replied to some of the points which had been raised, and the discussion was then closed by a few remarks from the chairman, Prof. Dixon.

\section{Progress in Engineering.}

THE James Forrest lecture delivered in r9o3 by Dr. W. H. Maw dealt with some unsolved problems of engineering; his presidential address, read before the-Institution of Civil Engineers on November 7 , directs attention to the progress which has been made towards the solution of certain of these problems. In ordinary researches the conclusions arrived at often remain untested for more or less long periods, and when they are tested it is not unusual for such tests to develop facts which, if known earlier, would have decidedly affected the character of the research carried out. During the war, especially in aeronautical researches, immediate results were wanted, and reasonable suggestions arising from research were, as a rule, tested without delay. As a result conclusions were arrived at and advances made much more promptly than would have been possible under other conditions.

For many years past there has been steady growth in the demands for larger structures and machines. In the case of bridges there are three ways in which increases of span may be made commercially attainable: First, by improvements in the structural designs; second, by the reduction of the so-called factors of safety now adopted; third, by the use of improved structural materials and constructive details. Dr. Maw does not think that there is much chance of obtaining material aid by the first of these methods ; it does not appear likely that any new type of design will be evolved possessing striking advantages as compared with those already known and investigated. The prospects from the second method are better; there are two classes of allowances, namely, (a) stresses due to wind pressures, changes of temperature, and so on, which depend upon local circumstances and other matters of individual judgment, so that a reduction cannot be calculated upon, and $(b)$ allowances which depend upon the quality of all the materials used and the soundness of the workmanship. The allowances under the latter head might be materially reduced as compared with those considered necessary even ten years ago. During that period, vast improvements have been made in our steel manufacturing processes, especially in the direction of ensuring uniformity of quality, while the facilities for thorough testing and inspection have been enormously increased.

In reference to the third way, there are no indications that we have reached the limits of progress in the use of improved structural materials. In long span bridges, the importance of the "specific tenacity " of the material (i.e. the ultimate strength in tons per sq. inch divided by the weight in pounds of one cubic inch) is exceedingly great, since the weight of the structure itself forms the larger portion of the total load supported. The successful manufacture, on a commercial scale, during recent years, of various high-quality alloy steels has quite changed the aspect of affairs and has materially enlarged the limits of the practically permissible spans of different types of bridges. At present, the most hopeful line of progress appears to lie in still further improvements in alloy steels and their treatment. Research work bearing on this subject is being vigorously prosecuted by our leading steel makers and affords every ground for expecting substantial advances.

Improvements in metallic alloys have been rendered possible by the revelations of microscopical research. Prior to the development of this type of analysis, 